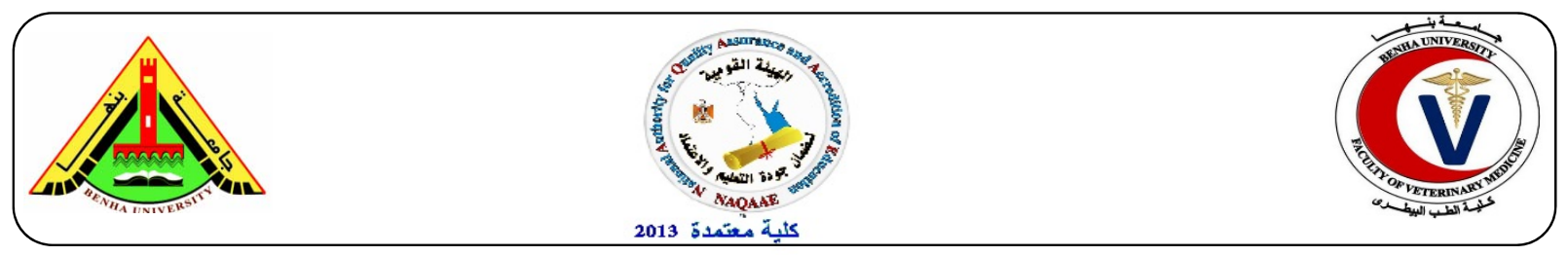

\title{
Sero-diagnosis of brucellosis in Gharbiya governorate, Egypt.
}

\author{
Lobna M. A. Salem ${ }^{1}$, Nashwa O. Khalifa ${ }^{1}$, Khoudair, R. M. ${ }^{2}$ and Samar M. M. Moustafa ${ }^{1}$ \\ ${ }^{1}$ Department of Zoonoses, Faculty of Vet. Med., Benha University. \\ ${ }^{2}$ Brucella Research Department, Animal Health Research Institute, Dokki.samar.mustafa@fvtm.bu.edu.eg
}

\begin{abstract}
A B S T R A C T
A total 1006 animals (300 cattle, 300 buffaloes, and 300 sheep and106 goats) were selected from private farms and suspected to suffer from brucellosis from different localities in Gharbiya governorate, as well as 50 rats (31Rattus rattus \&19 Rattus norvegicus) and 15 stray dogs were collected from the same localities associated with examined animals. In addition, 160 persons suffering from fever suspected to be brucellosis were collected ( 80 workers contact with examined animals and 40 from fever hospitals). Serological tests were carried out by using Rose Bengal plate (RBPT), Buffered Acidified plate test (BAPAT), Complement Fixation test (CFT), Tube Agglutination test (TAT) and 2- Mercapto-Ethanol test (2-MET). The results showed that the percentage of positive reactors were $9 \%, 7.3 \%, 9.3 \% 8.5 \%, 8 \%$ and $0 \%$ using RBPT in cows, buffaloes, sheep, goats, rats and dogs respectively. Meanwhile the percentage of positive reactors using BAPAT was $9.6 \%, 8.3 \%, 10.7 \%$, and $9.6 \%$ in cows, buffaloes, sheep and goats and by using CFT the percentage was $9.3 \%, 8 \%, 10.3 \%$ and $10.3 \%$ in previously examined animals. Also the result of TAT was $8 \%$ in rats and $0.0 \%$ in dogs. The occurrence of brucellosis in sheep and goats was higher than cows and buffaloes. Finally, the results in humans were $13.1 \%, 11.3 \%$ and $10 \%$ by using RBPT, TAT and 2 MET respectively. The incidence of brucellosis was higher in males $(14.9 \%)$ than females $(3.8 \%)$ and higher in humans aged between $20-30$ years.
\end{abstract}

Keywords: Brucellosis, serology, reservoirs, Egypt.

(http://www.bvmj.bu.edu.eg)

(BVMJ-31(1): 10-16, 2016)

\section{INTRODUCTION}

Brucellosis is a zoonotic worldwide infectious disease of animal that is caused by a number of adopted species of Gram-negative facultative intracellular bacteria of the genus Brucella, leading to tremendous economic losses as well as a potentially debilitating infection in man (Hosein et al., 2010). Diagnosis of Brucellosis depends on the use of efficient serodiagnostic tests. However, no single test is capable to identify all positive cases (Al-Habaty et al., 2015) as some animals are irregular in their immune response according to such factors as the dose, gestation stage, clinical status and presence of latent carriers (Alton, 1990) as well as difficulty in detection of incubation period of diseased animals or in detecting chronically latent infected cases. Therefore, combination of serological tests should be done to reduce the number of false negative serological reaction which contributes to the persistence of herd problem and also to reduce the number of false positive reaction to avoid over condemnation with test and slaughter policy. The diagnostic serological tests used in the present study were (BAPAT) as a quick simple and qualitative screening test in sera derived from different animals, (RBPT) as a quick simple and qualitative screening test in both sera from humans and animals under investigation, (CFT) in animals as standard quantitative test and confirmatory test to the previous screening tests to find the most sensitive and specific diagnostic test or tests could be adapted under regional condition of Egypt for diagnosis of brucellosis,(TAT) as standard quantitative test in humans besides (2-MET) was used for accurate diagnosis and elimination of nonspecific agglutinating antibodies in human sera. Rapid and accurate diagnosis is fundamental for control and eradication of Brucellosis (Refai 2002).

So the aim of this study is to clarify the occurrence of brucellosis in different animal reservoirs and to determine the most reliable tests to be adapted for control of disease in Egypt.

\section{MATERIAL AND METHODS:}

\subsection{Samples.}


Animal Blood samples: A total of 1006 animals (300 cows, 300 buffaloes, 300 sheep and 106 goats) were selected from private farms and suspected to suffer from brucellosis from different localities in Gharbiya governorate. Blood samples were taken aseptically by veni puncture, where the skin over the jugular vein was prepared by clipping, defatted by rubbing with a swab soaked in alcohol, then disinfected by tincture iodine. About $10 \mathrm{ml}$ of blood were aseptically collected into vacuum bottle. The collected samples were marked, identified and transferred to the laboratory. The clear sera were taken and stored at $2-8{ }^{\circ} \mathrm{C}$ for $48 \mathrm{hrs}$ in the refrigerator till use, if not used for days must be kept froze (Alton et al., 1988). 50 rats (31Rattus rattus \&19 Rattus norvegicus) were trapped by ordinary wire spring traps from different localities associated with the examined animals. Proteinious baits used to give more chance for trapping. Rat blood samples were collected from each rat by cardiac puncture with a sterilized needle in sterilized Wasserman tubes. These tubes left at room temperature in a sloping position for 30 minutes, then placed in the refrigerator overnight to give chance for sera to separate. Sera were obtained by using a sterile Pasteur pipette for serological studies (Moch et al., 1975) and 15 stray dogs were collected from the same localities associated with examined animals. Blood were taken from the cephalic vein, which is located on the cranial aspect of the foreleg; the animal is restrained in sternal recumbency or in a standing position with a sterilized needle in sterilized Wasserman tubes. These tubes left at room temperature in a sloping position for 30 minutes, then placed in the refrigerator overnight to give chance for serum to separate. Sera were obtained by using a sterile Pasteur pipette for serological examination (Bassert and Thomas, 2002).

Human Blood samples: A Total of 160 blood samples from persons suffering from fever suspected to be brucellosis were collected ( 80 workers contact with examined animals and 40 from fever hospitals) male and females at different ages. Blood samples were collected from brachial vein in sterile free clotting factor vacuum tube. Allowing blood to clot and sera were separated by centrifugation at $3000 \mathrm{rpm}$ for $10 \mathrm{~min}$ then divided into $2 \mathrm{ml}$ eppendorf tubes and stored at $-20^{\circ} \mathrm{C}$ until used for serological investigation.

\subsection{Serological examinations}

Rose Bengal plate Test (RBPT): it was done according to (OIE, 2015) using Brucella abortus antigen for RBPT. This is an $8 \%$ Rose Bengal stained Br. abortus strain 99 cells in lactate buffer $\mathrm{pH}(3.65 \pm 0.05)$.

Buffered Acidified plate Antigen Test (BAPAT) This test was done according to (OIE, 2015) using Brucella abortus antigen for BAPAT. It is a crystal violet brilliant green stained $\mathrm{Br}$. abortus strain 99 cells at a concentration of $11 \%$ in lactate buffer $\mathrm{pH}$ (3.7 \pm 0.03$)$.

Tube agglutination tests (TAT): The test was carried out according to Alton et al. (1988) using Standard tube agglutination antigen (TAT). The antigens were kindly obtained from Veterinary Serum and Vaccine Research Institute., Abbassia, Cairo, Egypt and usually stored at $4{ }^{\circ} \mathrm{C}$. It brought outside the refrigerator before its use in the test to reach room temperature.

The 2-Mercapto-Ethanol test (2-MET): The technique of the European tube mercapto-ethanol test used in this work according to Alton et al., (1975) using 2 Mercapto- Ethanol $(0.1 \mathrm{~mol} / \mathrm{litre}$ Mercapto-Ethanol solution in normal saline.

Complement fixation test (CFT): The test was done as described OIE, (2015) by warm fixation method using Brucella abortus concentrate. United States Department of Agriculture standard tube test concentrate $(4.5 \%$ Br. abortus biovar 1 strain 1119 3 cells in phenol saline/final PH 6.8). It was kindly offered by the National Veterinary Service Laboratories (NVSL), Ames, USA.

\section{RESULTS}

The obtained results in the Table (1) showed the results of different serological tests among different animal species. The percentage of positive reactors were $(9.6 \%, 9 \%$ and $9.3 \%$ among cows), $(8.3 \%, 7.3 \%$ and $8 \%$ among buffaloes), $(10.7 \%, 9.3 \%$ and $10.3 \%$ among sheep) and (10.3\%, $8.5 \%$ and $10.3 \%$ among goats) using BAPAT, RBPT and CFT respectively. The relative lower percentage of positive reactors detected by RBPT $(8.5 \%)$ than CFT $(9.3 \%)$ and BAPAT (9.6\%). Consequently, the occurrence of brucellosis in rats Table (1) revealed that $4 / 50(8 \%)$ were positive to Brucella out of them 3/31(9.7\%) belong to Rattus rattus and one out of $19(5.3 \%)$ belongs to Rattus norvegicus. The obtained results indicated that examined dogs were free from brucellosis. In this study, the occurrences of Brucella infection in examined persons detected serologically using RBPT, TAT and 2-MET Table (2) and revealed that the obtained results by RBPT (13.1\%) was higher than TAT (11.3\%) and 2-MET $(10 \%)$. Concerning the highly susceptible age to contract Brucella infection in human using RBPT. Table (3) it was found that the infection rate was 
Table (1) Results of different serological tests in different animal species.

\begin{tabular}{lcccccccccc}
\hline \multirow{2}{*}{ Animal species } & \multirow{2}{*}{$\begin{array}{c}\text { Total } \\
\text { No. }\end{array}$} & \multicolumn{2}{c}{ BAPAT } & \multicolumn{2}{c}{ RBPT } & \multicolumn{2}{l}{ CFT } & \multicolumn{2}{c}{ TAT } \\
\cline { 3 - 11 } & & & $+\mathrm{ve}$ & $\%$ & $+\mathrm{ve}$ & $\%$ & $+\mathrm{ve}$ & $\%$ & $+\mathrm{ve}$ & $\%$ \\
\hline Cows & 300 & 29 & $9.6 \%$ & 27 & $9 \%$ & 28 & $9.3 \%$ & - & - \\
Buffaloes & 300 & 25 & $8.3 \%$ & 22 & $7.3 \%$ & 24 & $8 \%$ & - & - \\
Sheep & 300 & 32 & $10.7 \%$ & 28 & $9.3 \%$ & 31 & $10.3 \%$ & - & - \\
Goats & 106 & 11 & $10.3 \%$ & 9 & $8.5 \%$ & 11 & $10.3 \%$ & - & - \\
Rats & 50 & - & - & 4 & $8 \%$ & - & - & 4 & $8 \%$ \\
Dogs & 15 & - & - & 0 & $0 \%$ & - & - & 0 & $0 \%$ \\
Total & 1071 & 97 & $9.6 \%$ & 90 & $8.4 \%$ & 94 & $9.3 \%$ & 4 & $6.2 \%$ \\
\hline
\end{tabular}

Table (2): Summarized Results of serological tests in (160) examined persons.

\begin{tabular}{ccccccccc}
\hline \multirow{3}{*}{ No. of samples } & & \multicolumn{2}{c}{ RBPT } & \multicolumn{2}{c}{ TAT } & \multicolumn{2}{c}{ 2-MET } \\
\cline { 3 - 8 } & & No. & $\%$ & No. & $\%$ & No. & $\%$ \\
\multirow{3}{*}{160} & Positive & 21 & 13.1 & 18 & 11.3 & 16 & 10 \\
& & & & & & & \\
& Negative & 139 & 86.9 & 142 & 88.8 & 144 & 90 \\
\hline
\end{tabular}

Table (3) Occurrence of Brucella infection among examined persons regarding to age and gender.

\begin{tabular}{cccccccccc}
\hline & $\begin{array}{c}\text { Total } \\
\text { No. }\end{array}$ & \multicolumn{3}{c}{ Males } & \multicolumn{3}{c}{ Females } & \multicolumn{3}{c}{ Total positive } \\
& $\begin{array}{c}\text { Age } \\
\text { examined } \\
\text { persons }\end{array}$ & No. & $+\mathrm{ve}$ & $\%$ & No. & $+\mathrm{ve}$ & $\%$ & No. & $\%$ \\
\hline$<20$ & 23 & 21 & 2 & 9.5 & 2 & 0 & 0.0 & 2 & 9.5 \\
$20-30$ & 49 & 42 & 10 & 23.8 & 7 & 0 & 0.0 & 10 & 47.6 \\
$30-40$ & 38 & 29 & 5 & 17.2 & 9 & 1 & 11.1 & 6 & 28.6 \\
$40-50$ & 33 & 28 & 3 & 10.7 & 5 & 0 & 0.0 & 3 & 14.3 \\
$>50$ & 17 & 14 & 0 & 0.0 & 3 & 0 & 0.0 & 0 & 0.0 \\
Total & 160 & 134 & 20 & 14.9 & 26 & 1 & 3.8 & 21 & 13.1 \\
\hline
\end{tabular}


high in $20-30$ years $(47.6 \%)$ followed by $30-40$ years $(28.6 \%), 40-50$ years $(14.3 \%)$ and $<20$ years $(9.5 \%)$. Also evident that the infection rate was higher in males $(14.9 \%)$ than females $(3.8 \%)$.

\section{DISCUSSION}

The diagnostic serological tests used in the present study were (BAPAT) as a quick simple and qualitative screening test in sera derived from different animals, (RBPT) as a quick simple and qualitative screening test in both sera from humans and animals under investigation, (CFT) in animals as standard quantitative test and confirmatory test to the previous screening tests to find the most sensitive and specific diagnostic tests could be adapted under regional condition of Egypt for diagnosis of brucellosis,(TAT) as standard quantitative test in humans besides (2-MET) was used for accurate diagnosis and elimination of nonspecific agglutinating antibodies in humans sera. Table (1) indicated that BAPAT gave higher positive rate than RBPT among the different animals' species. These results come in accordance with (El -Diasty 2004, Lobna 2006, Montasser et al., 2011, Hammad 2013 and El- Shymaa 2014) who reported that BAPAT was the most sensitive test also The same conclusion was also reported by (Ali et al. 2005, Khoudair et al. 2009 and Amin et al. 2012) who reported that the use of BAPAT as a presumptive test is recommended for its higher sensitivity and specificity. Moreover, an advantage reported to BAPAT is due to the acidic $\mathrm{pH} 4$ of its antigen which reduces the frequency of nonspecific reaction to the agglutination test. (El Sharkawy, 2004, Ali et al. 2005 and Saleh et al., 2006). On the other hand, the relative lower percentage of positive reactors detected by RBPT than BAPAT may be due to the fact that RBPT antigens has acidity of $\mathrm{pH} 3.65$, and this lower $\mathrm{pH}$ inhibits the activity of $\operatorname{IgM}$ and enhance the agglutination of IgG only. (Abdel Moghney, 2004, Ali et al. 2005 and Amin et al., 2012), while BAPAT has $\mathrm{pH} 4$ which permits the detection of IgM as well as IgG even IgG1 which is not agglutinating material at neutral $\mathrm{pH}$, is active at low pH of BAPAT. (Abdel Moghney 2004, Ali et al. 2005 and Shalaby 2013). This explains why BAPAT is more sensitive than RBPT.

Employing of complement fixation test in this study revealed the lowest number of reactors than BAPAT. The test gave negative results in some serum samples that were identified as reactors in other tests, Such reactions may be regarded as false positive reactions, which may be attributed to the presence of some gram negative bacteria which share brucella in its antigenicity and thus crossreact with the used antigen (El Sharkawy 2004), So to minimize the cross reaction with other organisms (E. coli, Salmonella dublin, Yersinia enterocolitica O:9 and Pasteurella tularensis), which produce a great number of false positive reactors, it was decided to carry out the complement fixation test on the same sera samples. Our results are in agreement with (Shalaby et al., 2003, Radostits et al. 2007 and Azzam et al. 2009). The complement fixation test detect primarily $\mathrm{IgG}_{1}$ and the presence of $\operatorname{IgG}_{1}$ correlated with the state of actual infection even if present in small amount. This makes the CFT is a more reliable test due to the higher sensitivity and specificity in picking up infected cases and is still superior among the employed tests as reported by (Khoudair 2004, Radostitset al. 2007 and Azzam et al. 2009).

The difference between the results of various tests employed may be due to difference in the sensitivity of various tests to various antibodies or variation of $\mathrm{pH}$ of different antigens in these tests and the stage of infection. The results obtained from serological studies revealed that the infectious rate of disease among examined animals was higher in sheep and goats than in cattle and buffaloes. Similar results were obtained by (Lamyaa 2005, Lobna 2006, Noha et al., 2007 and Abeer 2013). Dealing with detection of Brucella agglutinins in serum samples collected from 50 rates by using RBPT as a rapid screening test. Table (1) indicated that $4(8 \%)$ were positive to Brucella out of them $3(9.7 \%)$ belong to Rattus rattus and the reminder $1(5.3 \%)$ belongs to Rattus norvegicus. This finding was similar to that obtained by Lobna (2006). The results of the present study showed existence of Brucella infection among rats in Egypt. These rats act as reservoirs to Brucella and transmit infection to domestic animals and man by contaminating pastures, food or water troughs with their discharges (Salem et al., 1974). Therefore, rats in Egypt act as a potential source for dissemination of Brucella infection and this should be taken in consideration in organizing control programs for eradication of brucellosis.

In this study, Brucella agglutinins in serum samples collected from 15 dogs examined by using RBPT and TAT indicated that examined dogs were free from brucellosis. These results are similar to those previously obtained by Mrunalini and Ramasastry (2000), on contrast, (Mateu-de- 
Antonio et al., 1994 and Hinić et al., 2012) detected Br.melitensis in examined dogs' sera. In human, Table (2) revealed that the obtained result by RBPT $(13.1 \%)$ was higher than TAT $(11.3 \%)$ and 2-MET $(10 \%)$. RBPT found to be highly sensitive for detection human brucellosis and this result agree with (Mac-Millan1990) recorded that the RBPT is more accurate indicator for Brucella infection than serum agglutination test. Moreover, (Corbel et al., 2007) suggested that RBPT test is similar to SAT test and highly sensitive than TAT agglutination test besides it's easier of application while 2Mercapto Ethanol test (2-MET) disrupts disulphide bonds making $\operatorname{IgM}$ antibodies inactive and permitting only Brucella agglutination by $\operatorname{IgG}$ agglutination antibodies that resistant to $2 \mathrm{ME}$ (Edward et al., 2006)

Concerning the highly susceptible age to contract Brucella infection using RBPT Table (4) it was found that the infection rate was high in 2030 years $(47.6 \%)$ followed by $30-40$ years $(28.6 \%)$, $40-50$ years $(14.3 \%)$ and $<20$ years $(9.5 \%)$ this may be referred to the fact that the majority of the workers in veterinary field, abattoir, milkers and animals attending aged 20-40 years (Wafaa et al., 2003). These findings agree with (El-Moghazi, 1998, Lobna, 2006 and Abeer, 2013).

Concerning the infection with brucellosis in males and females in this study Table (4) revealed that the infection was higher in males $14.9 \%$ than females $3.8 \%$ these results were agreed with (Moyer et al., 2009) who stated that worldwide, males were affected more than females with ratio of 5:2to 5:3 in endemic areas this may attributed to man take infection through occupational exposure (Christie, 1987) Also, The highest positive percent in male may be due to male had higher exposure than female to different risk factor and to aborted , dealing to high number of infected animals and may be consume row milk or row dairy product from infected animals with brucellosis. These results were in agreement with (Ibrahim et al., 2002 and Samaha et al., 2008). It can be concluded that: The highest seroprevalence of brucellosis in human and animals (cow, buffaloes, sheep and goats) in the same region leading to consider those animals main source of brucellosis for human through exposure to infected animals (aborted material \& discharge of infected animals) or consumption of raw milk contaminated with Brucella species and contact with infected rats.

Rats act as potential source for dissemination of Brucella infection. The buffered acidified plate antigen test is an effective test for initial screening of brucellosis in farm animals as it is more sensitive than rose bengal plate test, simple easy, quick and inexpensive test.
No single serological test could be identifying all stages of brucellosis in infected animals, Complement Fixation test is still the superior one among the employed tests as it gave the highest balance of sensitivity and specificity.

\section{REFERENCES}

Abdel Moghney, A.F. 2004. preliminary study on brucellosis on camels at Behira province. Ass. Univ. Bull. Environ. Res., 7 (1): 39-43.

Abeer, M. A. 2013. Determination and Evaluation of different types of Brucella species infecting human and animals. Ph.D. Thesis, Zoonosis, Fac. Vet. Med., Cairo University.

Al-Habaty, S. H., Abuo-Gazia, K. A., Ammar, M.A.M. 2015. Prevalence study on brucellosis in some ruminants slaughtered out of abattoir in Assuit Governorate. Assiut Vet. Med. J. Vol. 61 No. 144- January.

Ali, M.M., Makar N.H., Scddck S.R. 2005. Serological study of brucellosis on camels in Assiut and the New Valley governorates. Assiut Vet. Med. J., 51 (105): 158-164.

Alton, G.G. 1990. Brucella melitensis. In: Nielsen, K. and Duncan, J.R. (Editors), Animal Brucellosis. CRC Press Inc., Boca Raton, pp. 383-409.

Alton, G., Jones, L., Angus, R., Verger, J. 1988. Techniques for the brucellosis laboratory. Institut National de la Recherché Agronomique, Paris.

Alton, G.G., Jones, L.M., Pietz, D.E. 1975. Laboratory techniques in brucellosis. WHO Geneva. offset publ. (55): 145-148.

Amin, M.M., Ahmed, S.A., Zaki, H.M., Ismail, R.I. 2012. Serological and molecular studies on the diagnosis of bovine brucellosis. Nature and Science, 10 (11): 68-76.

Azzam, R.A., El-Gamal, A.M., El-Sheemy, M.T. 2009. Failure of control of Brucella melitensis infection in dairy herds. Assiut Vet. Med. J., 55 (121): 174-285.

Bassert, J. M., Thomas, J. A. $2002 . \quad$ Clinical text book for Veterinary Technicians, $5^{\text {th }}$ ed. (2002).

Christie, A.B. 1987. Infectious diseases. Epidemiology and clinical practice. 3rd ed, Edinburgh: London and New York, Churchill Livingstone: pp.1139.

Corbel, M.J., Stuart, F.A., Brewer, R.A. 2007. Observations on serological cross- reactions between smooth Brucella species and organisms of other genera. Developments in biological standardization,56: 341-349. 
Edward, M., Thomas, B., Luke, T. 2006. 2Mercapto ethanol Brucella agglutination test: usefulness for predicting recovery from brucellosis. J. Micro. 11(1):691-693.

El-Diasty, M.M. 2004. Epizootiological and immunological studies on bovine brucellosis. MVSc. Thesis, Infectious diseases Faculty of Vet. Med, Suez Canal University

El-Moghazi, M. G. 1998. Epidemiological studies on Brucellosis in farm animals, occupational contacts and patients with fever of unknown origin (F.U.O). Ph.D. Thesis, (zoonosis) Fac. Vet. Med., Cairo University.

El-Sharkawy, H. I. M. 2004. Studies on sensitivity and specificity of some serological tests used for diagnosis of brucellosis in cattle. M.V.Sc. Thesis (Infectious Diseases), Faculty of Veterinary Medicine, Cairo University, Beni-Suef.

El-Shymaa, A. A. 2014. Recent techniques for diagnosis of brucellosis in farm animals. MVSc, Thesis, Infectious diseases, Faculty of Vet. Med, Zagazig University.

Hammad, O. H. 2013. Comparison between different serological tests for accurate diagnosis of brucellosis in animal and mycoplasmosis in poultry. $\mathrm{Ph}$. D. Thesis, Vet. Sc. (microbiology) Faculty of Vet. Med. Kafr el sheikh University.

Hinić, V., Brodard, I., Petridou, E., Filioussis, G., Contos, V., Frey, J., Abril, C. 2012. Brucellosis in a dog caused by Brucella melitensis. Rev 1. Vet. Microbiol., 141 (34), 391-392.

Hosein, H.I., Ghabashy, A.A., Azzam, A.A., Elsherif, A.M., Sassi, M.F. 2010. Nitric oxide and lysozyme activities as early monitors of the immune response of Brucella abortus RB51 vaccinated cows. First Vet. Med. Conference, Libya, 3-5 July.

Ibrahim, A.K.; Ibrahim, I.G.; Ghoneim, M.A.; Awad, W.S. 2002. Evaluation of Polymerase Chain Reaction (PCR) and conventional brucellosis diagnostic techniques in milk samples from different animal species. J. Egypt. Vet. Med. Assoc., 62 (2): 119-131.

Khoudair, R. M. 2004. Map of cattle brucellosis in some governorates of Egypt. Ph.D, Thesis (Microbiology), Faculty of Veterinary Medicine, Alexandria University.

Khoudair, R.M., Ibrahim, E.M., Saker, G.G., Hafez, M.A. 2009. Clinicodiagnostic and pathological studies on cattle and buffaloes suffering from brucellosis and tuberculosis in Kafr El Sheikh Governorate. Egypt. J.
Comp. Path. \& Clinic. Path. 22 (1): 148 174

Lamyaa, M. A.B. 2005. puplic health importance of brucellosis in Menofia Governorate. Ph.D. Thesis, Zoonoses, Fac. Vet. Med., Benha University.

Lobna, M. A. 2006. Epidemiological studies on Brucellosis in animal and man with special reference to prevention and control. Ph.D. Thesis, Zoonosis, Fac. Vet. Med., Benha University.

Mac-Millan, A. 1990. Conventional serological test in animal brucellosis. Cited in (an approach towards the use of some un conventional serological tests for the diagnosis of brucellosis. M.V.SC. By Ashraf, E.S(1995).

Mateu-de-Antonio, E. M., Martin, M., Casal, J. 1994.Comparison of serologic tests used in canine brucellosis diagnosis. J Vet Diagn Invest.; 6:257-259.

Moch, R.W., Ebner, E.E., Barsoum, I.S, Botros, B. A. 1975. Leptospirosis in Ethiopia: A serological survey in domestic and wild animal. J. Trop. Med. And hyg., 78: 38-42.

Montasser, A.M., Affi, M.M., El-Bayoumy, E.M., Abdul-Raouf, U.M., Mohamad, H.A. 2011. Efficiency of Serological Tests for Detection of Brucellosis in Ruminant at South Provinces of Egypt. Global Vet. 6 (2): 156161.

Moyer, N.; Holcomb, A; Pike, R. 2009. Brucella in: Manual of clinical microbiology. Washington DC:ASM press: 549-555.

Mrunalini, N., Ramasastry, P. 2000. Serological survey on the occurrence of brucellosis in domestic animals and man in Andhra Pradesh. Indian. Vet. J., 76 (6): 483- 484.

Noha, H.M., Asmaa, A.A., Hussien, K., Ismail, A.A., Elias, A.H., Abdel-Kader, H.A. 2007. The use of ELISA for diagnosis and epidemiology of infection in some farm animals in Assiut Governorate. Vet. Med. J. Giza, 55 (3): 851-865.

OIE, 2015. Bovine Brucellosis. Section 2.3 in OIE manual of Standards for diagnostic tests and vaccines.

Radostits, O. M., Gay C. C., Hinchcliff, K.W., Constable, P.D. 2007 Veterinary Medicine. 10th ed. Elsevier Saunders, London. 389390.

Refai, M. 2002. Incidence and control of brucellosis in the Near East region. Vet. Microbiol, 20; 90 (1-4): 81- 110.

Saleh, M.A., Badawy, A.I., Mohamed, E.M. 2006. Update status of toxoplasmosis and brucellosis in small ruminants and human in 
Sharkia province. Vet. Med. J. Giza, 45 (1): 75-85.

Salem, A.A., Hamed, O.M., Abdel-Karim, A.M. 1974. Studies on some Brucella carriers in Egypt. Assiut. Vet. Med. J. 12: 184-187.

Samaha, H.; Al-Rowaily, M.; Khoudair, R.M.; Ashour, H.M. 2008. Multicenter Study of Brucellosis in Egypt. Emerg. Infect. Dis., 14 (12): 1916-1918.

Shalaby, N., Gafer, J., Badran, M.A. 2013. Serological and molecular differentiation between Brucella and Yersinia enterocolitica 0:9 infections in cattle. Assiut Vet. Med. J., 59 (139): 1-8.
Shalaby, N.; Ghobashy, H.; El-Ballomy, E..; Saleh, W. 2003. Prevalence of brucellosis among farm animal species in some Governorates in Egypt. 7th Sci. Cong., Egyptian Society for Cattle Diseases, Assiut, Egypt.

Wafaa, S. M. A., Ghobashy, H. M., El-Bayoumi, E. M., Shalaby, M. N. H. 2003. Diagnosis of human brucellosis among animal farm workers and patients with fever of unknown origin using both conventional and recent techniques $7^{\text {th }}$ Sci. Cong., Egyptian Society for Cattle Disease, 7-9 Dec., Assiut, Egypt. 